\title{
Heat Transfer Performance of a Two Phase Closed Corrugated tube Thermosyphon
}

$$
\text { أذاء انتقال الحرارة لسيفون مفلق ذو سطح متعرح }
$$

\section{H. H. Sarhan}

Mechanical Power engineoring dept, Facuily of Engineerıng in Port said. Suez Canal University, Egypl

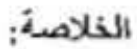

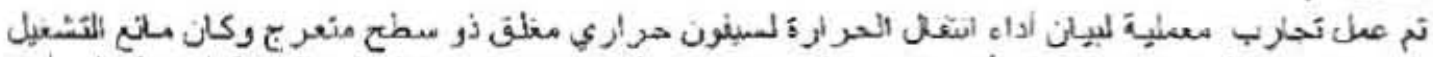

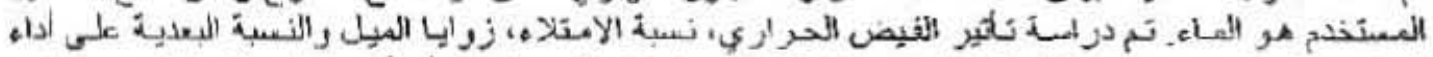

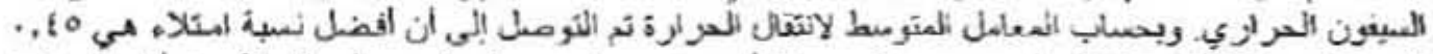

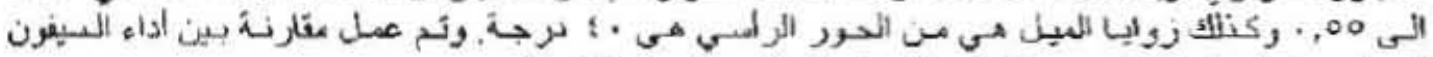

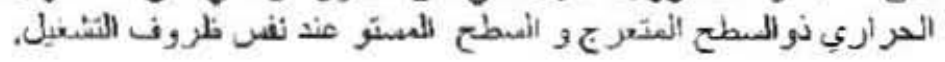

\begin{abstract}
The two phase closed Thermosyphons are highly sufficient heat transfer element. At present, however, actual applications are mostly limited for thermosyphon using smooth tube as its container. In the present work, a corrugated. tube was used as its container with distilled water as the working fluid. The corrugated tube container is flexible and has several features to allow the thermosyphon to be used in a wide range of applications. The influence of liquid filling ratio, inclination angle, evaporator heat fiux and condenser to cvaporator length ratio on the heat transfer performance was experimentally studied. The experiments are carried out for values of heat flux of $11,20.5,32.8,44 \mathrm{~kW} / \mathrm{m}^{2}$, Filling ratios of $20,40,60,80$ and $100 \%$ with respect to evaporator volume for each thermosyphon configuration are used. The effect of inclination angles of zero, 20, 40,60,80 and 90 degrees measured from the vertical axis is examined. Three different values for length ratios between condenser to evaporator of $1,1.5$ and 3 are used. According to the measured values of problem parameters, the mean heat transfer coefficient is calculated. It is found that the optimum filling ratio is in the range of $40-60 \%$ for both smooth and corrugated tubes. In addition, the maximum performance is obtained at inclinationjangle of 40 degree. Moreover, a comparison is made between cortugated tube and smooth tube at the same tested parameters.
\end{abstract}

$\begin{array}{cl}\text { Nomenclature } \\ \text { A } & \text { Area } \\ \text { d } & \text { Tube diameter } \\ \text { L } & \text { Thermosyphon length } \\ \text { q } & \text { Heat flux } \\ \text { Q } & \text { Heat transfer rate } \\ \text { T } & \text { Temperature } \\ \text { U } & \text { Mean heat transfer coefficient } \\ \text { X } & \text { Axial coordinate of the tested tube }\end{array}$

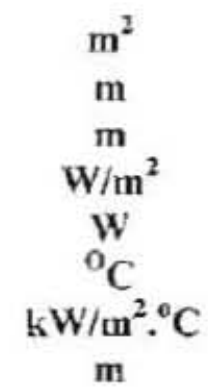

Greek symbols:

$\varepsilon \quad$ Filling ratio

$\$$ Inclination angle Deg.

Subscripts:

c Condenser

e Evaporator

Accepted December I, 2008 


\section{Introduction}

The thermosyphons are heat transfer devices of relatively high thermal conductivity. During the last 40 years, several configurations of the thermosyphon are proposed and developed, often as an alternative to the heat pipe. They are of interest for different fields such as heat exchanger, turbine blade cooling, electronic component cooling, heat recovery systems, devices for solar energy utilization, permafrost stabilization and numerous industrial and space applications. Imura et. al [1983] studied experimentally the critical heat flux in a closed two-phase thermosyphon. The effect of inside diameter, heated length, working fluid, fill charge and inside temperature on the critical heat flux are investigated. They found that the critical heat flux is increased with increasing the fill charge in a region called dry-out region, since the dry area appears as a result of the film breakdown. Sawada $e t$. al [1983 and 1995] presented an experimental study on the heat transfer performance of an inclined two-phase closed thermosyphon. The amount of working fluids and the inclination angle are experimentally studied. It is concluded that, in order to obtain a steady high heat transfer rate it is necessary to fill between $25-60 \%$ of the evaporator inner volume with water as the working fluid. Also, the inclination angle must be between $20^{\circ}$ and $40^{\circ}$ for working fluid. The heat transfer in the heating and cooling zones of a closed thermosyphon tube is studied experimentally by Gross and Hahne [1985]. Refrigerant-115 is used as a working fluid in the near critical state. In is found that the optimum inclination angle is obtained at about $40^{\circ}$ form the vertical position. Visual observation of flow patterns in the condenser and heat transfer measurements are obtained by
Maezawa and Takuma [1988] using a vertical annular thermosyphon.

Refrigerant-115 is used also as a working fluid. It is shown that ripples [interfacial waves] are generated on the condensatc film surface. Ueda et. al [1989] performed an experiment with vertically arranged closed two-phase thermosyphon. The condensation heat transfer coefficient of the cooling section shows a trend to decrease with increasing wall temperature difference. Tanaka and Koshino [1994] performed a scries of experiments with a copper-water wickless heat pipe. The influence of working fluid charge and inclination angle on the heat transfer coefficients of the evaporator and the condenser is studied. The experimental results indicated that as the heat transfer coefficient in the case of the liquid film is larger than that in case of liquid pool, Lin and Shyu [1995] studied experimentally the geyser boiling in a vertical annular closed two-phase thermosyphon. It is indicated that it occurred more frequently and irregularly at high heat load. Shalaby et. al [2000] presented an experimental study on the heat transfer performance of low temperature two-phase closed thermosyphon using $\mathrm{R} 22$ as a working fluid. The effect of liquid charge ratio and inclination angle on the heat transfer performance was studied. Sultan et. al [2003] investigated experimentally the viberated two-phase closed thermosyphon using R134a. The effect of heat flux, filling ratio, viberation frequency and amplitude were experimental paraneters. K. Negishi [1991] studied experimentally the evaporator performance of corrugated tube thermosyphon with water as a working fluid. The influences of liquid charge ratio and inclination angle on the heat transfer performance were studied. . Park and Lec [1992] made an experimental study on the performance 
of two-phase closed thermosyphons with three working fluid mixtures (waterglycerin, water-ethanol, and waterethylene glycol). They found that for all values of filling ratio, the tested thermosyphon had the highest performance at an inclination angle of about $60^{\circ}$ from the direction of the gravitational force. Gunnerson and Zuo, [1995] studied theoretically the heat transfer characteristics of an inclined two-phase thermosyphon. Shiraishi et al.,[1995] conducted a flow visualization study of the inside flow phenomena of an inclined two-phase closed thermosyphon. They used R113 as a working fluid. Terdtoon et al. [1996] investigated the effect of aspect ratio (ratio of evaporator section length to diameter) and Bond number on the heat transfer characteristics of an inclined two-phase closed thermosyphon. They used R22, ethanol, and water as working fluids, and a filling percentage of $80 \%$. They found that hie aspect ratio and Bond number did not affect the angle at which the highest heat transfer rate occurred. The heat transfer in a vertical annular twophase closed thermosyphon has been studied experimentally with distilled water as a working fluid by Abdel-Aziz, [1996]. The effects of hcat fiux, liquid fill charge, and evaporator to condenser length ratio on the heat transfer coefficient, was investigated. He showed that the maximum overall heat transfer coefficient occurred at an evaporator to condenser length ratio ranged between 0.33 to 1.0 , and the liquid fill charge was about $16 \%$ based on the total thermosyphon inside volume. AbouZiyan, et al. [2000] made an experimental study of a two- phase closed thermosyphon to predict its performance characteristics. They used water and R134a as working fluids. They investigated the effects of the filling ratio, and the length of adiabatic section on the output heat flux for a wide range of input heat flux with water as a working fluid for stationary experiment. They investigated also the effects of vibration on the output heat flux using water and R134a as working fluids. The frequency range was varied from 0 to $3.33 \mathrm{~Hz}$. Ferguson and Lilieteht, [1996] presented a model of therm-vibrational convection in a vertical cylindrical cavity, and studied the frequency dependence of heat transfer rate through the system at several Rayleigh numbers, and vibrated Grashof number. Shiraishi et al., [1996] investigated experimentally the critical heat transfer rate in an inclined two-phase closed thermosyphon. They investigated the effects of the ratio of evaporator length to inner tube diarneter, fill charge, working fluid property, and operating pressure. Shalaby et al., $[2000]$ presented an experimental study on the heat transfer petformance of low temperature two-phase closed thenmosyphon. Theit experiunents were performed to investigate the effect of heat flux, filling ratio (volume of the working fluid to the evaporator volume), and the angle on the performance of low temperature two-phase closed thermosyphon. They used R22 as a working fluid. Rosler et al., [1987] presented an experimental and theoretical investigation of heat transfer characteristics of a vertical annular closed two-phase thermosyphon. They used RI13 as a working fluid

The aim of the present work is to study experimentally the flow and heat transfer in a closed two-phase corrugated tube thermosyphon. Liquid filling ratio, inclination angle, heat flux and length ratio are considered as tested parameters. 
M. 18

H. H. Sarhan

\section{Experimental Apparatus}

A schematic layout of the experimental work test rig is shown in figure (1). The thermosyphon tube consists of three main parts: evaporator, condenser and adiabatic tubes. The three main parts are made of a copper corrugated tube of 1000 mm total length, $32 \mathrm{~mm}$ inside diameter, $1.5 \mathrm{~mm}$ wall thickness and $5 \mathrm{~mm}$ corrugation pirch with 2 $\mathrm{mm}$ wave height.

The evaporator tube is 315 $\mathrm{mm}$ effective length. The bottom of which is also welded to a small copper tube having a thermocouple wire to measure the temperature at the center of the evaporator.

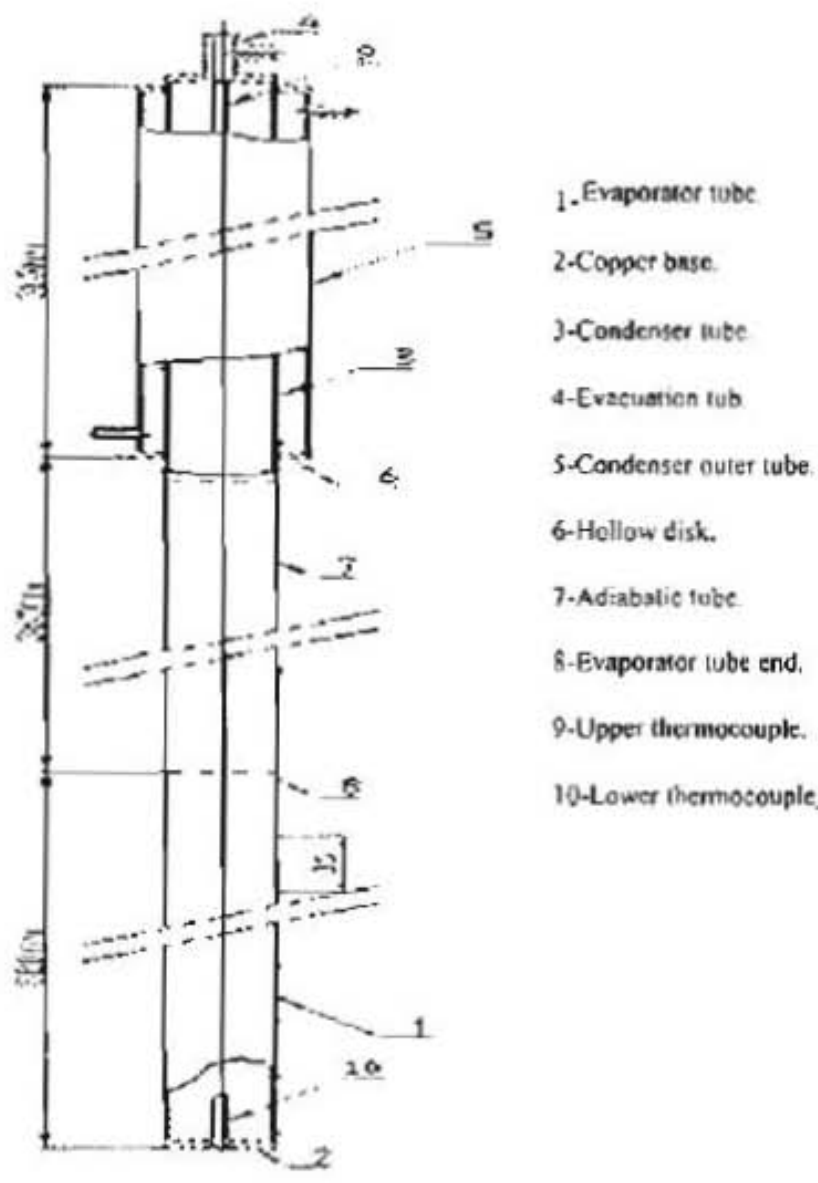

Figure (1) Experimental layout

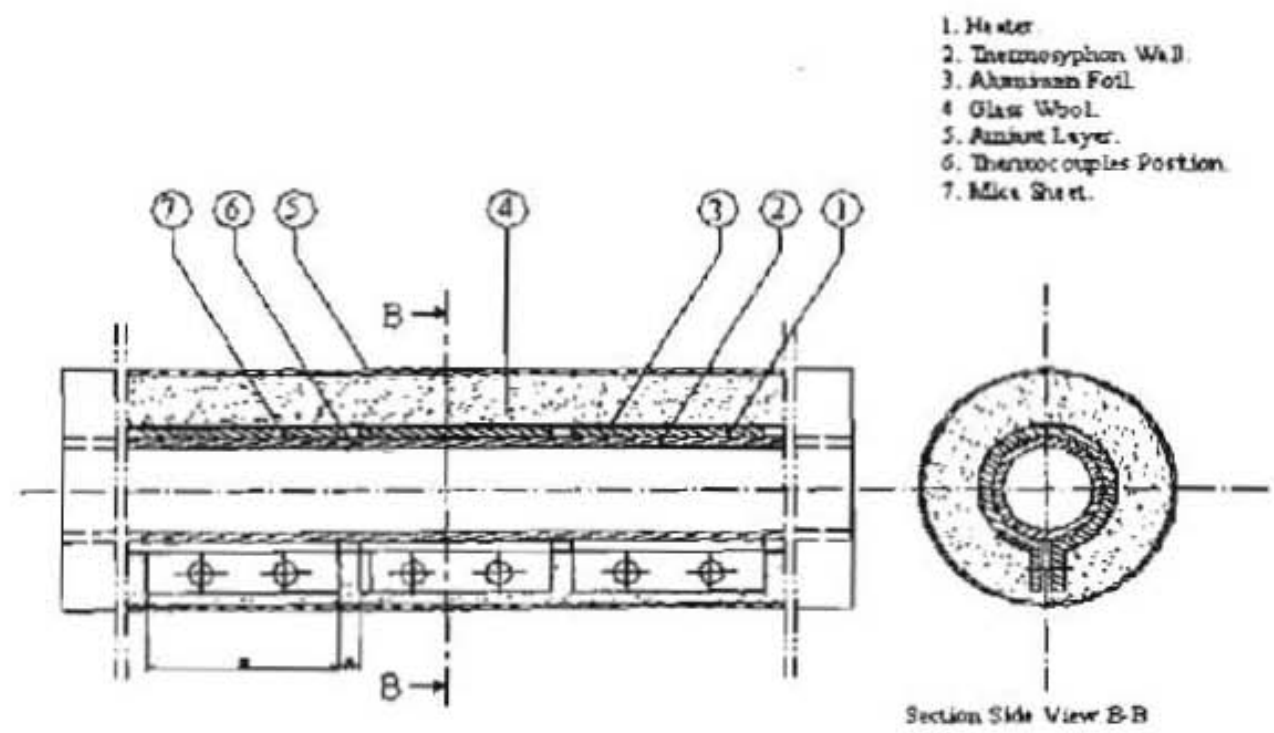

Figure (2) Details of evaporator section 
The evaporator is divided into three equal parts and heated by three $\mathrm{A}$. C. separated electrical heaters of $1.5 \mathrm{~kW}$ maximum power. The heater in each section is also divided into three identical heater elements each with max power of $0.5 \mathrm{~kW}$ as shown in figure (2). The heaters are mounted on the evaporator outer surface by means of bolts. A reflective aluminum foil sheet is used to enclose the evaporator with the heaters to ensure maximum reflection of heat generated by the heaters to the

evaporator surface. A layer of thermal insulation followed by additional reflective aluminum foil sheet is wrapped on the outer surface.

The electrical power supplied to the evaporator heaters is measured in the usual way with an ammeter and voltameter. The value of stabilized voltage can be adjusied by using a variable voltage power supply. The connection and the disconnection of the heaters in each section, in parallel manner, vary the evaporator length, and consequently the value of the adiabatic length. The heat lost to the atmosphere is estimated by measuring the temperature of the insulation outer layer and ambient temperature.

Referring to figure (1), the condenser is of double-pipe type, in which the inner corrugated pipe is the upper section of the thermosyphon with $315 \mathrm{~mm}$ effective length. The outer pipe is made of copper tube of $50 \mathrm{~mm}$ outer diameter with city water as coolant. The top of the condenser is welded to a valve. and the valve is connecied to a T-shape joint one of it's end is attached with the pressure gauge and the other end is fitted to a vacuum line and the chatge line. Also, it is welded to a small tube having a thermocouple to measurc the vapor temperature inside the condenser tube.

A number of nine thermocouples (type T) are used to measure the temperature distribution along the evaporator outer surface of the evaporator. Similarly, temperanure distribution along the outer surface of the inner pipe of the condenser soction is measured by six thermocouples. Temperature is measured on the adiabatic tube by two thermocouples. A protractor mechanism is designed and constructed to perform the inclination angle of the thermosyphon. This mechanism allows the thermosyphon to tilt in a vertical plane containing the evaporator and the condenser with $10^{\circ}$ minimum reading. Positive inclination angle is defined as the clockwise tilt. The themosyphon is evacuated using vacuum pump and
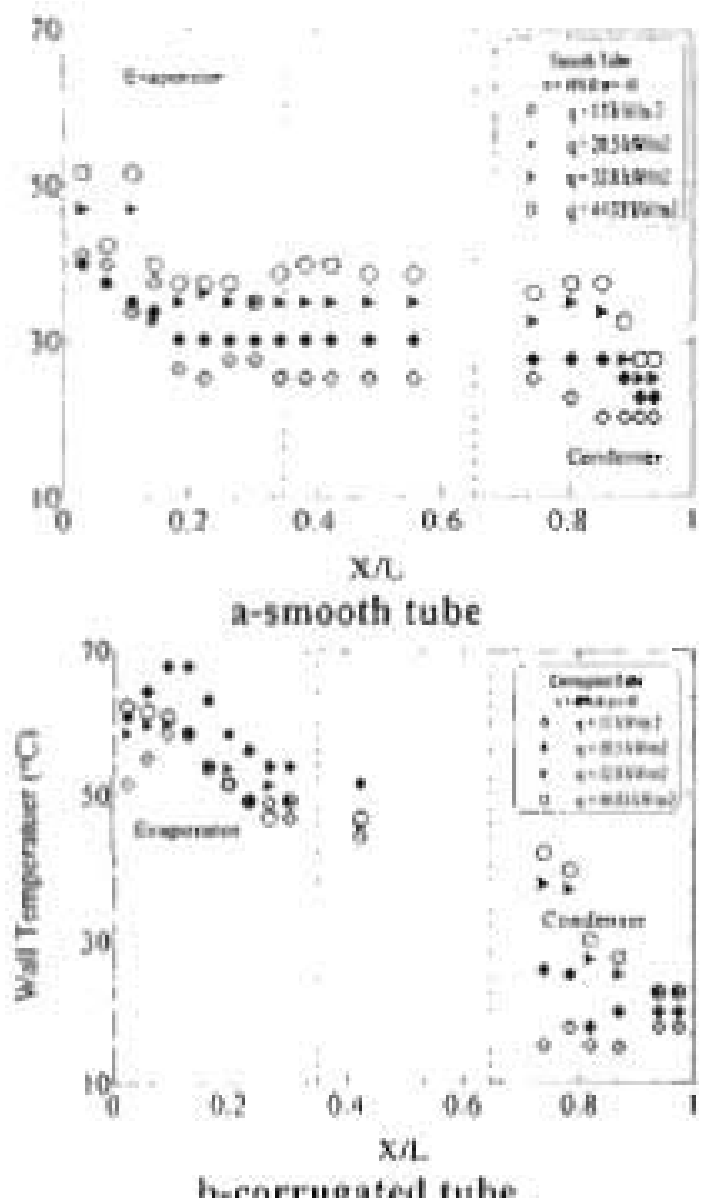

Figore (3) Temperature distribution along thermosyphon wall 
charged with adequste amount of distilled water. Before charging the thermosyphon, some precautions are noticed and taken into account to ensure good operation and performance. The thermosyphon tube must be cleaned in order to ensure that the working fluid wets the tube wall and removes any foreign materials, which would create incompatibilities. All welds are checked for leaks.

For the application of thermosyphon, the heat transfer coefficient in a particular zone (evaporator or condenser) is of less interest than the overall heat transfer coefficient (which gives the indication of the ability of the tube to transport heat).

The overall heat transfer coefficients of the thermosyphon, the evaporator section, and the condenser section are defined, respectively, as:

$$
\begin{aligned}
& U=q /\left(T_{e m}-T_{c m}\right)=1 / 1 / \mathrm{h}+L^{\prime} / M_{q}
\end{aligned}
$$

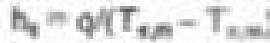

$$
\begin{aligned}
& h=q /\left(T_{k-m}-T_{i n}\right)
\end{aligned}
$$

Correction is made for the outside surface tube temperatures to obtain the inside surface temperatures and is found to be less than $0.04^{\circ} \mathrm{C}$.

Where, $\mathrm{C}_{1} \mathrm{U}, \mathrm{A}, \mathrm{T}_{\mathrm{m}}$ and $\mathrm{T}_{\mathrm{m}}$ are the generated heat rate, the mean heat trausfer coefficient of thernosyphon, the cvaporator surface area, the average surface temperature of the evaporator section and the surface temperature of the condenser section respectively.

\section{Results and Discussion}

The measured temperature along the thermosyphon wali and the calculated mean heat transfer coefficient are reported. The effect of various parameters, controlling the system on the heat trinsfer process is discussed.
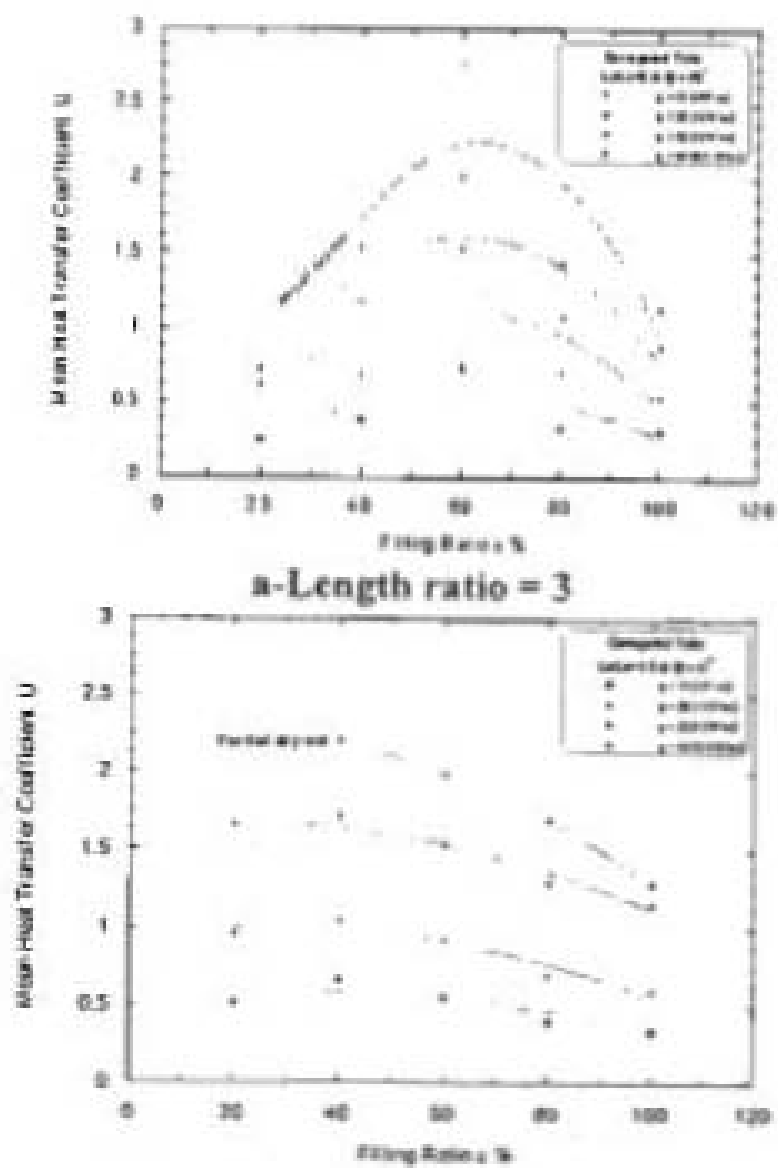

b- Length ratio $=1.5$

Figure (4) Effect of filling ratio on mean beat transfer coefficient for inclination

\subsection{Temperature Distribution}

Figures $(3 a-b)$ show the temperature distribution for smooth tube and corrugated tube respectively along the evaporator and condenser walls for different values of heat flux and length ratios, "ratio between condensers to heated length" of 3 for filling ratio $40 \%$, and $40^{\circ}$ inclination angle. These figures indicate that the value of temperature at all measuring points is directly proportional to the value of heat flux. It increases also with the increase of the evaporator length. Also it's clear that the temperature distribution for the smooth tube is lower than that of corrugated tube and this is because the smooth surface of the smooth tabe allows the return condensate to the evaporator easily but 
Mansoura Engineering Joumal, (MEJ), Vol. 33, No. 4, December 2008.

the corrugation surface of the corrugated tube makes the condensate relurn slowly.

\subsection{Eifect of Filling Ratio}

Figures $(4 a-b)$ indicate the relation between mean heat transfer coefficient (U) and filling ratio $(\varepsilon)$ for heat fluxes of $11,20.5,32.8$ and 44.03 $\mathrm{kW} / \mathrm{m}^{2}$ with length ratios of 1.5 , and 3 and $60^{\circ}$ inclination angle. It is clear that the mean heat transfer coefficient decreases with increasing the filling ratio till it reaches to its maximum at filling ratio $60 \%$ in case of length ratios 3 and $40 \%$ for length ratios of 1.5 and 1 . It is clear also that the mean heat transfer coefficient increases with the increase of the heat flux. For length ratios 1.5 (and 1) partial dry-out appeared at filling ratio $20 \%$ for high heat fluxes, is because the
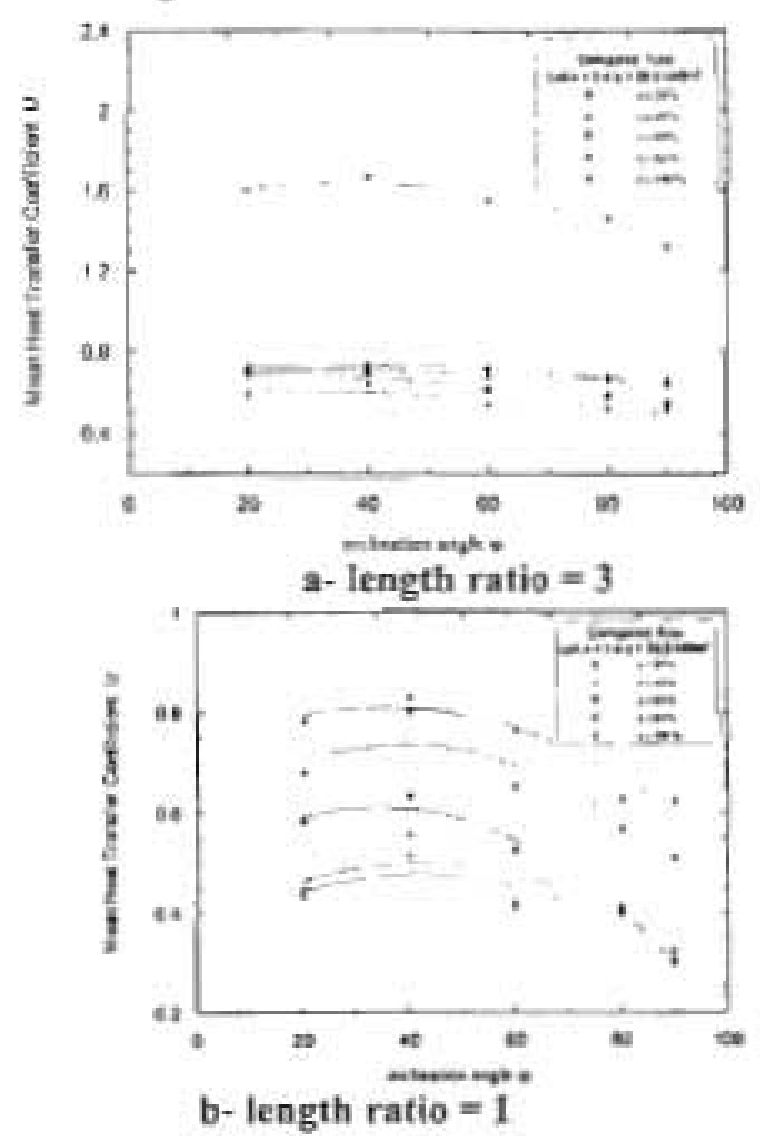

Figure (5) Effect of inclination angle on menn heat transfer coefficient for length ratio 3 ; corrugated tube increase of the heat flux and the length ratio in case of $(20 \%)$ filling ratio this small anount of water could not reach the end of the evaporator and dry-out. On the other wise for large filling ratios ( 80 and $100 \%$ another phenomenon appeared that is the working fluid flooding making a strange sound like smacks.

\subsection{Effect of Inclination Angle}

Figures $(5 a-b)$ represent the relation between the mean heat transfer coefficient and inclination angle for filling ratios of $20,40,60,80$ and $100 \%$, and a heat flux of $20.5 \mathrm{~kW} / \mathrm{m}^{2}$ for length ratios of 3 and 1 in case of corrugated tube. It is clear that the mean heat transfer coefficient is incrcased with the increase of the inclination angle till it
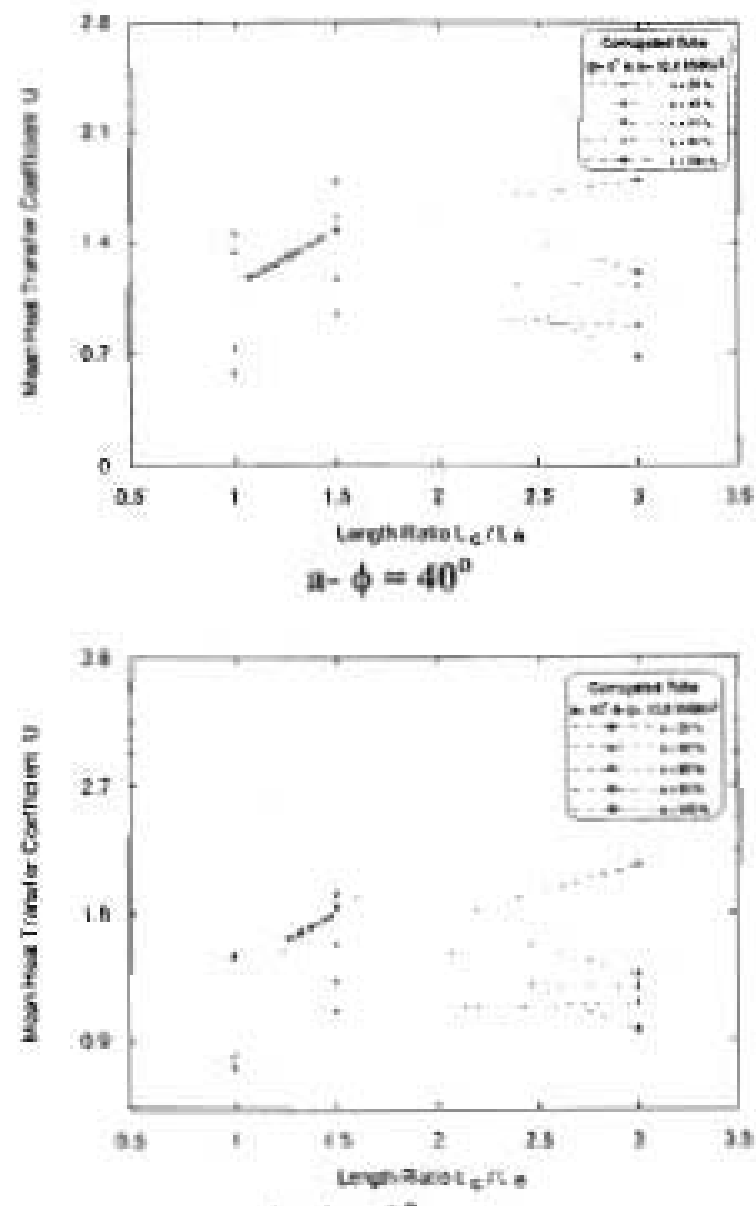

b- $\phi=0^{\circ}$

Figure (6) Effect of length ratio on mean heat transfer coefficient for $40^{\circ}$ inclination angle; corrugated tube. 
reaches a maximum value at $40^{\circ}$ inclination angle then it decreases once more. For length ratio 1 , it is clear that it have the same trend as the length ratio 3 but the mean heat transfer coefficient on the case of length ratio 3 is higher than that at the length ratio 1 . This is because the decreasing of the length ratio affects the return condensate and make the increases of surface temperature.

\subsection{Effect of Length Ratio}

Similarly, to study the effect of length ratio (Lc/Le) which in turn clarifies the effect of adiabatic length, the mean heat transfer coefficient (U) is plotted versus the ratio ( $\mathrm{Lc} / \mathrm{Le}$ ) for different values of the filling ratio and a heat flux of $32.8 \mathrm{~kW} / \mathrm{m}^{2}$ and inclination angles of $0^{\circ}$ and $40^{\circ}$ shown in figures (6ab). The analysis, of the obtained data reveals that, the mean heat transfer coefficient increase with increasing length ratio (increasing adiabatic length) for the tested filling ratio. At filling ratios, rather than optimum ( $40 \%$ for corrugated tube and $60 \%$ for smooth tube), and length ratio of 3 the mean heat transfer coefficient is decreased sharply. It is clear that, as the length ratio increases the descending condensate in the cooled section will be thicker than the heated ascending one "due to the increased capability of the condenser" , this cases relatively reasonable feeding by working fluid to the heated section. On the contrary, as the length decreases at relatively greater heated length the condensate will be thin and the scattering of the liquid on the adiabatic section should be significant. This leads to the dryness of the evaporator section, which can be viewed as a tendency toward increasing the overall thermal resistance of the system.

\subsection{Comparison between Smooth and Corrugated Tube Thermosyphon}

Figures (7a-b) illustrate a comparison between the smooth tube and
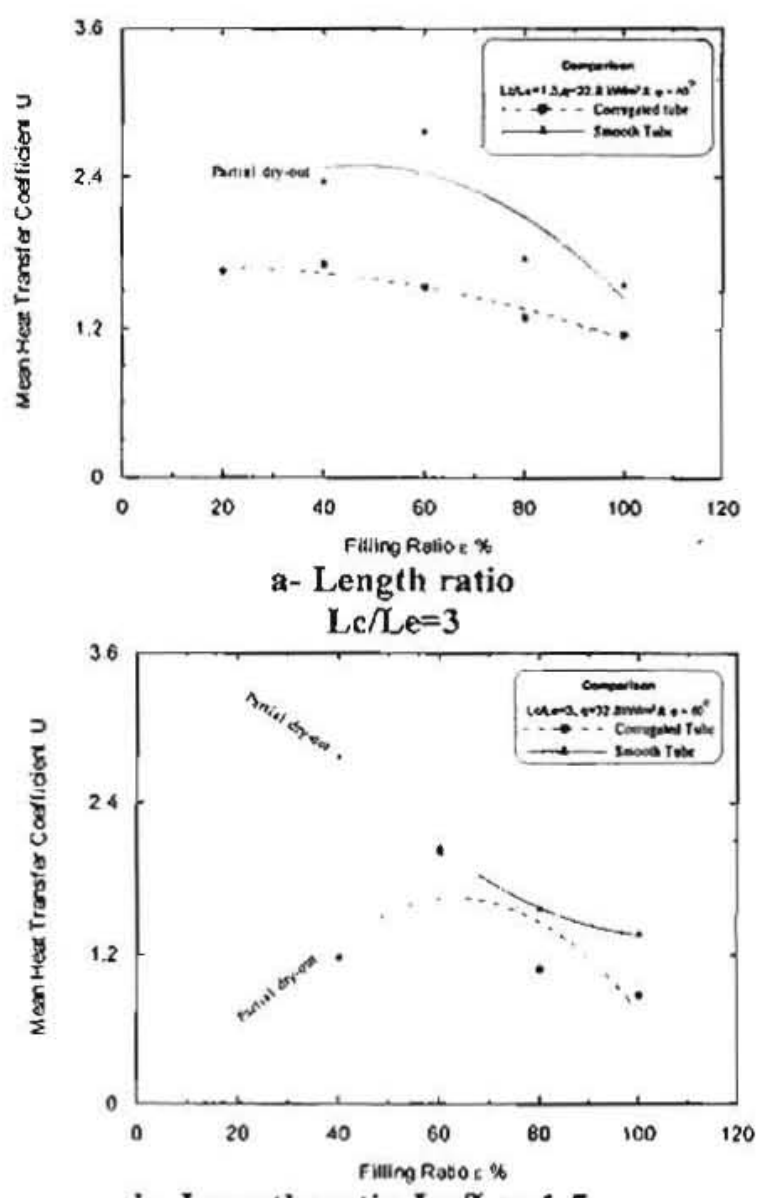

b- Length ratio $\mathrm{Lc} / \mathrm{Le}=1.5$

Figure (7) Mean heat transfer coefficient for Smooth tube and corrugated tube thermosyphon for inclination angle of $60^{\circ}$

corrugated tube thermosyphon for heat flux of $32.8 \mathrm{~kW} / \mathrm{m}^{2}$ and $60^{\circ}$ inclination angle at different values of filling ratios and length ratios. It is indicated that for length ratio 3 the smooth tube thermosyphon have max mean heat transfer coefficient at $40 \%$ filling ratio and the corrugated tube at $60 \%$ filling ratio. This is expected, since the use of corrugated tube increases overall flow resistance. On the contrary, for both length ratios 1.5 (and 1) the smooth tube thermosyphon have its maximum mean heat transfer coefficient at filling ratio of $60 \%$, and the corrugated tube at $40 \%$ filling ratio. 


\section{Correlating the Experimental Data}

The present experimental data was correlated in a dimensionless form. This correlation represents the Nusselt number as a function of filling ratio $\left(\mathrm{V}^{*}\right)$, and reduced pressure $\left(\mathrm{P} / \mathrm{P}_{\mathrm{ct}}\right)$. The empirical heat transfer correlation for thermosyphon was correlated as:

$$
\begin{aligned}
& \left.\mathrm{Nu}=2382 \mid\left(\varepsilon^{+}\right)^{-0.25}(\mathrm{Ku})^{0.361}\left(\mathrm{P} / \mathrm{P}_{\mathrm{Cr}}\right)^{-0.64}\right] \\
& \text { for } \varepsilon^{+}>\varepsilon^{*} \text { ost (4) } \\
& \mathrm{Nu}=3144 \mid\left(\varepsilon^{+}\right)^{-0.75}(\mathrm{Ku})^{0.371}\left(\mathrm{P} / \mathrm{P}_{\mathrm{er}}\right)^{-0.001} \text {, } \\
& \text { for } \varepsilon^{\circ}<\varepsilon^{\circ} \text { opt }
\end{aligned}
$$

Where:

$\mathrm{Nu}$ Nusselt number, $=\mathrm{U} d_{1} / k_{1}$

$\mathrm{Ku} \quad$ Kutateladze number $=$ $(\mathrm{Q} / \pi \mathrm{DL} /) /\left(\mathrm{h}_{\mathrm{fg}}\left[\sigma \mathrm{g} \rho_{v}^{2}\left(\rho_{1}-\rho_{v}\right)\right]^{1 / 4}\right)$

$\varepsilon^{*}$ filling ratio

$\varepsilon^{+}$opt optimum filling ratio

$\mathrm{P} / \mathrm{P}_{\mathrm{er}}$ reduced pressure

and $1276.2 \leq q \leq 6331 \mathrm{~W} / \mathrm{m}^{2}, 0.3 \leq \mathrm{e}^{*} \leq 1.0$. $0.23 \leq \mathrm{P} / \mathrm{P}_{\mathrm{ct}} \leq 0.3$

The maximum deviation between the present experimental data and the deduced correlations are $\pm 7.0 \%$ and \pm $8 \%$ respectively.

\section{Conclusion}

Based on the results obtained in the present investigation it is found that, the smooth tube having higher mean heat transfer coefficient than the corrugated tube. In order to obtain high heat transfer performance, it is necessary to fill between $40 \%$ and $60 \%$ of the evaporator inner volume. For most examined conditions, inclination angle, measured from vertical axis, of $40^{\circ}$ for corrugated tube and $60^{\circ}$ for smooth tube improves the mean heat transfer performance. For the tested filling ratios and inclination angles, the length ratio of 1.5 gives maximum heat transfer coefficient. An excessively low charge $(20 \%)$ of the working fluid into the thermosyphon results in evaporator dry-out, causing a low heat transport. On the other hand, an excessively high charge $(80-100 \%)$ of working fluid results in reduction of effective condensation heat-transfer surface, also causing a lower heat transport

The obtained empirical correlations may be considered as a helpful tool for studying the rate of heat transfer from the thermosyphon. The agreement between these correlations and the obtained experimental results is quite good.

\section{REFERENCES}

1. H. Imura, $\mathrm{K}$. Sasaguchi and $\mathrm{H}$. Kozai (1983), "Critical heat flux in a closed two-phase thermosyphon," Int. J. Heat Mass Transfer, Vol. 26, pp. $1181-188$.

2. T. Sawada and K. Negishi (1983), "Heat transfer performance of an inclined closed two-phase thermosyphon," Int. J. Heat Mass Transfer, Vol. 26, pp. 1207-1213.

3. T. Sawada and M. Shiraishi (1995), "Visual study on flow behavior in an inclined closed two-phase thermosyphon," J. Heat Transfer Engineering, Vol. 16, pp. 53-59.

4. U. Gross and E. Hahne(1985), "Heat transfer in a two-phase thermosyphon operating with a fluid in the near critical statc," Int. J. Heat Mass Transfer, Vol. 28, pp. 589-601.

5. S. Maezawa and M. Takuma (1988), " Heat transfer characteristics of the R113 annular two-phase closed thermosyphoo," JSME series II, Vol. 31 , pp. $469-476$.

6. T. Ueda, T. Miyashita and P. Chu (1989), "Heat transport characteristics of a closed two-phase thermosyphon," JSME series II, Vol. 32, pp. 239-246.

7. O. Tanaka and $H$ Koshino(1994), "Heat transfer characteristics of a copper-water wickless heat pipe," JSME series B, Vol. 60, pp. 28262832 
8. T. F. Lin and R. J. Shyu (1995), "Experimental investigation of geyser boiling in an annular two-phase closed thermosyphon," Int. J. Heat Mass Transfer, Vol. 38, pp. 295-307.

9. K. Ngisshi and T. Matsuoka (1991), "Heat transfer performance of a corrugated-tube thermosyphon. Part 1. Evaporation performance," Heat Transfer- Japanese Research, Vol. 20, pp. 144-157.

10. M. Shalaby, G. Sultan and M. Awad (2000), "Heat transfer performance of a two-phase closed thermosyphon," Proceeding of the $6^{\text {th }}$ International Heat Pipe Symposium Chiang Mai, pp.269-278.

11. G. Sultan, M. Shalaby and A. Abdel Salam (2003), "Heat transfer performance of a viberated two-phase closed thermosyphon,"Mansoura Engineering Journal,(MEJ). Vol. 28, No. 2, pp. 133-145.

12. Park, R. J., and Lee, Y, (1992) "Two-Phase Closed Thermosyphon with Two Fluid Mixture", Procceding of the $8^{\text {th }}$ International Heat Pipe Conference, Beijing. China, Vol.2 ,PP. 220-225, September 14-18.

13. Imura, H., Sasaguchi, K., and Kozai, H , (1993), " Critical Heat Transfer in a Closed Two-Phase Thermosyphon", Int. J. Heat Mass Transfer, Vol.26, No.8, pp.1181. 1188

14. Gunnerson F. S., and Zuo Z. J. (1995), Modeling of an Inclined Two-Phase Closed Thermosyphon, ASME / JSME Thermal Engineering Conference, Vol.2, pp. 27-34.

15. Shiraishi M. Terdtoon P., and Murakami M.,(1995), "Visual Study on Flow Behavior in an Inclined Two- Phase Closed Thermosyphon", Heat Transfer Eng., Vol.16, No.1, pp. 53-59.

16. Abdel-Aziz M.(1996), Experimental Analysis of the Optimum Performance of Closed
Vertical Thermosyphon Based on Geometry and Liquid Fill Rate Considerations, The $9^{\mathrm{t}}$ Int. Conf. For Mech. Power Eng., (ICMPE.9), Shebin El-Kom, Egypt, December, 21-24.

17. Ferguson, F. T., and Lilleteht, L. U (1996), "Thermovibrational Convection in a Vertical Cylinder", Int. J. Heat Mass Transfer, Vol. 39, No. 14. pp. 2895-2906.

18. Shiraishi, M., Young, I. K, Murakami, M., and Terdtoon, P 1996)" A Correlation for the Critical Heat Transfor Rate in an Inclined Two-Phase Closed Thermosyphon", Proceedings of the $5^{\text {th }}$ International Heat pipe Symposium, Melboume, Australia, pp. 248-254

19. Terdtoon P., Rittbidej S., and Shiraishi M. (1996), Effect of Aspect Ratio and Bond Number on Heal Transfer Characteristics of an Inclined Two-Phase Closed Thermosyphon at Normal Operating Condition, Proceedings of the $5^{\text {m }}$ International Heat Pipe Symposium, Melbourn, Australia, pp. 261-266.

20. Akihiro, S. (1996), " A Flexible Heat Pipe with Carbon Fiber Arterial Wick", $11^{\text {th }}$ International Heat Pipe Conference - Tokyo, Vol. 1, No. 1, pp.149-159.

21. Hedeaki I., Kenji I., and Shigetoshi 1 (1999), "An Experimental lnvestigation of Geysering in TwoPhase Closed Thermosyphons", $11^{\text {th }}$ international Heat Pipe Conference Tokyo, Vol. 1, No. 1, pp.166-171.

22. Peterson, G. P., and $\mathrm{Ma}, \mathrm{H}$. B, (1999)," Temperature Response of Heat Transport in a Micro Heat Pipe ", ASME Trans. J of Heat Transfer, Vol. 121, pp. 438-445.

23. Abou-Ziyan, H. Z., Helali, A. Fatouh, M., and Abo El-Nasr, M. M. , (2000)" "Performance of Stationary And Thermosyphon Working with Water And R134a." Proceeding of $11^{\text {th }}$ International Mechanical Power Engineering Conference, Cairo, Vol. 2, pp. 53-67. 